\title{
INICIAÇÃO À DOCÊNCIA: DISCUSSÕES SOBRE PLANEJAMENTO E PRÁTICAS DO PIBID LETRAS - PORTUGUÊS E ESPANHOL
}

\author{
Aline Cassol Daga Cavalheiro ${ }^{1}$ \\ Ana Cecília Teixeira Gonçalves ${ }^{2}$ \\ Cristiane Horst ${ }^{3}$ \\ Geni Vanderleia Moura da Costa ${ }^{4}$ \\ Jeize de Fatima Batista ${ }^{5}$ \\ Saulo Gomes Thimóteo ${ }^{6}$
}

1 Doutora em Linguística. Professora adjunta da Universidade Federal da Fronteira Sul (UFFS), coordenadora de área do Subprojeto de Língua Portuguesa (Campus Chapecó/SC) do PIBID-UFFS. Contato: aline.daga@uffs.edu.br

${ }^{2}$ Doutora em Letras. Professora adjunta da Universidade Federal da Fronteira Sul (UFFS), coordenadora de área do Subprojeto de Língua Portuguesa (Campus Cerro Largo/RS) do PIBID-UFFS. Contato: acgteixeira@uffs.edu.br

3 Doutora em Letras. Professora Associada da Universidade Federal da Fronteira Sul (UFFS), coordenadora de área do Subprojeto de Língua Portuguesa (Campus Chapecó/SC) do PIBID-UFFS. Contato: cristianehorst@uffs.edu.br

${ }_{4}$ Doutora em Letras. Professora adjunta da Universidade Federal da Fronteira Sul (UFFS), Coordenadora de área do Subprojeto de Língua Espanhola (Campus Cerro Largo/RS) do PIBID-UFFS. Contato: geni.costa@uffs.edu.br

5 Doutora em Letras. Professora adjunta da Universidade Federal da Fronteira Sul (UFFS), Coordenadora da área do Subprojeto de Língua Portuguesa (Campus Cerro Largo/RS) do PIBID-UFFS. Contato: jeize.batista@uffs.edu.br

${ }^{6}$ Doutor em Letras. Professor adjunto da Universidade Federal da Fronteira Sul (UFFS), coordenador da área do Subprojeto de Língua Portuguesa (Campus Realeza/PR) do PIBID-UFFS. Contato: saulo.thimoteo@uffs.edu.br 


\section{RESUMO}

O presente capítulo tem como objetivo discutir as experiências vivenciadas no Programa Institucional de Bolsas de Iniciação à Docência (PIBID), na área de Letras - Português e Espanhol da Universidade Federal da Fronteira Sul (UFFS), enquanto campo de construção do conhecimento docente. Desse modo, apresenta ações que vêm sendo desenvolvidas nos Cursos de Letras dos três campi da UFFS (Cerro Largo, Chapecó e Realeza), durante o período de vigência do Programa (2018-2019). Primeiramente, discorre sobre questões concernentes à organização e ao planejamento de ações, os quais tiveram como ponto central o desenvolvimento da consciência crítica e a formação do cidadão. Além disso, para finalizar, apresenta uma proposta de criação de materiais didáticos envolvendo a leitura, a literatura e as diversas etapas de ensino da Educação Básica. Com isso, busca mostrar a relevância de atividades relacionadas ao planejamento e à prática na constituição do profissional docente.

Palavras-chave: Formação inicial. Planejamento. Prática. Constituição docente.

\section{INTRODUÇÃO}

O Programa Institucional de Bolsa de Iniciação à Docência (PIBID) é uma proposta de incentivo ao processo de formação de docentes para Educação Básica. Tem como objetivo a qualidade das ações acadêmicas voltadas à formação inicial de professores, incluindo os graduandos no cotidiano escolar. Para isso, o PIBID Letras - Português e Espanhol da Universidade Federal da Fronteira Sul (UFFS) permite que alunos de licenciatura possam realizar as atividades pedagógicas em escolas públicas de Educação Básica, contribuindo para a integração entre teoria e prática, além da aproximação entre universidades e escolas.

A atuação dos pibidianos nas escolas é acompanhada pelos supervisores (professores das escolas) e pelos coordenadores de área (professores da UFFS), que desenvolvem atividades forma- 
tivas com esses alunos, no sentido de possibilitar reflexões sobre a ação docente, a fim de prepará-los para a inserção no ambiente escolar e, mais especificamente, no contexto da docência em Língua Portuguesa e/ou Língua Espanhola.

Nesse sentido, uma das questões centrais do Subprojeto PIBID Letras - Português e Espanhol da UFFS foi tomar o planejamento como tema norteador das atividades formativas e das ações desenvolvidas até o momento. O objetivo da formação acerca do ato de planejar, e, portanto, da importância de pensar, organizar, sistematizar, prever e decidir, é deixar claro aos pibidianos, docentes em processo de formação inicial, que a profissão docente demanda planejamento e reflexão contínua acerca das ações de ensino, quer seja em um nível micro ou nível macro. Do ponto de vista educacional, o planejamento é um ato político-pedagógico, relacionado ao cidadão que se deseja formar (BARROS LEAL, 2005). Em nossa compreensão, pensar sobre a prática, antes, durante e depois do desenvolvimento das ações pedagógicas, é essencial do ponto de vista do ensino.

Nessa perspectiva, o objetivo deste capítulo é apresentar algumas experiências vivenciadas no PIBID, na área de Letras - Português e Espanhol da UFFS, destacando o papel do planejamento e a sua importância na construção do conhecimento docente. Na primeira parte do capítulo, discutimos questões relacionadas à organização e ao planejamento de ações que tiveram como foco a conscientização crítica e a formação do cidadão. Em seguida, apresentamos uma proposta de criação de materiais didáticos envolvendo a leitura, a literatura e as diversas etapas do Ensino Fundamental e Ensino Médio.

\section{PRÁTICAS VOLTADAS PARA A CONSCIENTIZAÇÃO CRÍTICA E PARA A FORMAÇÃO DO CIDADÃO}

A proposta do PIBID Letras - Português e Espanhol da UFFS está relacionada à organização e à concepção das atividades 
que envolvem o projeto. Importa salientarmos que o objetivo primordial é destacar a relevância do planejamento na construção docente, na organização e no desenvolvimento de atividades que tenham como foco a conscientização crítica e a formação do cidadão. Assim, em todas as atividades, desde a formação dos pibidianos até o planejamento das aulas que ministram nas escolas, consideramos de extrema importância

[...] compreender a cidadania como participação social e política, assim como exercício de direitos e deveres políticos, civis e sociais, adotando, no dia a dia, atitudes de solidariedade, cooperação e repúdio às injustiças, respeitando o outro e exigindo para si o mesmo respeito [...] posicionar-se de maneira crítica, responsável e construtiva nas diferentes situações sociais, utilizando o diálogo como forma de mediar conflitos e de tomar decisões coletivas. (BRASIL, 1998, p. 7).

Sob essa perspectiva, ao analisarmos o caminho percorrido até aqui, desde a entrada no Programa até a fase em que se encontra atualmente, é possível percebermos o processo de formação e de desenvolvimento profissional dos pibidianos e a consequente constituição do sujeito crítico, seja o professor em formação inicial, os supervisores, os coordenadores de área ou os estudantes matriculados nas escolas as quais participam do projeto.

Desse modo, assim que formada a equipe do PIBID, já no segundo semestre de 2018, os pibidianos tiveram vários encontros de formação para que pudessem alavancar os conhecimentos teóricos com momentos de leituras, produção escrita e seminários de debates. As reflexões desenvolvidas dentro do PIBID tornam-se um instrumento para se analisar a construção de saberes docentes, assim como de impactos, impressões, expectativas, contribuições e avanços que esse Programa, enquanto política pública, tem inserido à formação, tanto inicial de professores 
quanto à continuada em serviço. Alguns dos temas desenvolvidos nessa primeira etapa foram os seguintes: as dimensões do trabalho do professor de língua portuguesa e de língua espanhola; a formação de professores e o processo de aprendizado da atividade docente; as etapas do planejamento da ação docente; o ensino de línguas e sua relação com a inclusão; o preconceito linguístico; os contextos de multilinguismo nas escolas; diversidade linguística e cultural; o ensino e a aprendizagem de Espanhol como língua estrangeira; os documentos oficiais norteadores, como a Base Nacional Comum Curricular (BNCC); o texto como unidade de ensino; o uso dos gêneros textuais na sala de aula; o uso da internet no ensino de língua espanhola; a avaliação do texto do aluno; etc.

Além disso, todos os bolsistas, com acompanhamento das suas supervisoras, tiveram a oportunidade de participar do ambiente escolar, realizando observações, elaborando diários de bordo, reconhecendo o espaço sob um olhar atento de quem sai da posição de aluno, para posição de futuro professor, já antevendo e projetando possíveis projetos de docência, a se desenvolverem no segundo ano do subprojeto. As observações bem como as reflexões sobre essa etapa registradas no diário de bordo são ferramentas pedagógicas essenciais na formação inicial de professores, pois possibilitam o pensamento crítico-reflexivo. É importante salientar que as observações, que constituem a etapa de sondagem dentro do planejamento, também precisam ser planejadas. Assim, a preparação dos pibidianos, por meio de discussões sobre o objetivo dessa fase, é essencial para que a compreendam como uma prática reflexiva.

Dessa forma, podemos comprovar que os registros, as análises, as experiências, as observações e as socializações favorecem a criação de espaços de construção de um novo conhecimento, produzido nas relações entre instituições e sujeitos, integrando os diferentes saberes que constituem o conhecimento profissional.

Depois das leituras orientadas, encontros de formação, debates e experiências de observação, produção de ensaios e 
fichamentos, os pibidianos, no primeiro semestre de 2019, acompanhados pela coordenação e supervisão, iniciaram a elaboração dos projetos de docência e dos planos de aula para aplicação prática nas escolas. Nessa fase, em conformidade com as atividades de formação, a ação proposta pelo PIBID Letras - Português e Espanhol da UFFS é o planejamento de aulas que tenham como foco principal a formação cidadã dos sujeitos envolvidos. Desse modo, escolhe-se uma temática social que será o eixo organizador do processo de ensino. Nesse contexto, as práticas voltadas para o eixo da oralidade, da leitura, da escrita, dos conhecimentos linguísticos e gramaticais e da educação literária vinculam-se ao tema proposto. Vale ressaltarmos que essa ação está em consonância com o objetivo norteador da BNCC:

[...] garantir a todos os alunos o acesso aos saberes linguísticos necessários para a participação social e o exercício da cidadania, pois é por meio da língua que o ser humano pensa, comunica-se, tem acesso à informação, expressa e defende pontos de vista, partilha ou constrói visões de mundo e produz conhecimento. (BRASIL, 2018, p. 63).

É interessante destacarmos que, embora, em 2019, os estudantes tenham a atribuição de ministrar aulas, essa inserção em sala de aula não é direta: primeiramente, há o tempo de observação das aulas, em que são listadas características dos estudantes a fim de construir um diagnóstico da turma. Essa etapa, dentro da elaboração do planejamento, corresponde ao que se nomeia de sondagem, que consiste em "[...] investigar ou pesquisar a realidade, para poder, a partir da sua situação, pensar e preparar uma ação consciente, realista, organizada e apropriada para aquela situação determinada." (MENEGOLLA; SANT'ANNA, 2012, p. 72). Esse movimento de construção de um diagnóstico da turma contribui para a elaboração dos objetivos da ação docente.

Em seguida, a partir das especificidades listadas, inicia-se o processo de escolha de temáticas que guiarão o planejamento; 
logo, tem-se o processo de organização dos planos, os quais são orientados tanto pelos coordenadores do projeto quanto pelos supervisores. A seleção dos conteúdos a serem trabalhados pelos pibidianos nas escolas constitui-se em outra fase muito importante do planejamento. Com base nos critérios de seleção apresentados por Menegolla e Sant'Anna (2012), os pibidianos poderão refletir sobre as escolhas de conteúdo, de modo a terem clareza acerca da validade, da relevância, da interdisciplinaridade, da cientificidade etc., de cada temática selecionada. Para Barros Leal (2005, p. 3), em se tratando dos conteúdos, "[...] além do conhecimento da ciência, o professor, por exercer uma função formadora, deve inserir outros conteúdos: socialização, valores, solidariedade, respeito, ética, política, cooperação, cidadania, etc."

Assim, a seleção de conteúdos, que deve ser feita de forma conjunta entre supervisores e pibidianos, demanda planejamento em nível macro, uma vez que exige planejamento em longo prazo, prevendo atividades articuladas a projetos maiores da escola, e escolhas a partir da realidade social dos alunos. Sob esse viés, o foco das aulas de língua não estaria relacionado a um ensino de regras, de estruturas, de respostas prontas, que se dão de modo descontextualizado e artificial. Ao contrário, é a preocupação com o social, com a interação da realidade versus escola, com a problematização, com o questionamento permanente, a base norteadora de todas as práticas realizadas. A partir disso, trabalha-se de um modo descendente, do todo para a parte, do macro para o micro, em que as questões sociais motivam as questões linguísticas. Essa abordagem prevê a formação de um professor entendido como um "[...] sujeito capaz de considerar seu vivido, de olhar para o aluno como um sujeito que também já tem um vivido, para transformar o vivido em perguntas." (GERALDI, 2010, p. 95).

Por fim, antes de ocorrer a regência das aulas pelos pibidianos, aborda-se a questão da avaliação, a qual faz parte do planejamento e precisa ser tratada antes do exercício da prática. O planejamento de qualquer projeto ou ação demanda a decisão 
sobre como vai se dar a avaliação, considerando para isso os objetivos traçados e as possibilidades de ensino e aprendizagem (MENEGOLLA; SANT'ANNA, 2012). A avaliação permite, portanto, a reflexão sobre a prática pedagógica, sobre os processos de ensino e de aprendizagem, e é essencial dentro de um planejamento responsável.

Assim, trabalhamos com diversas temáticas, como a inclusão, as relações familiares, as relações sociais, o uso das tecnologias, a diversidade cultural etc. Também, tendo em vista um ensino mais inclusivo e plural, realizam-se atividades relativas à Língua Espanhola ${ }^{7}$, as quais buscam ampliar os espaços das linguagens em geral e garantir a oferta de uma língua estrangeira. Isso revela conhecimento da realidade linguística de nossas comunidades, visto que o mundo do trabalho - associado às facilidades de comunicação e locomoção internacionais - beneficia aqueles alunos com melhor acesso ao ensino qualificado, o qual certamente inclui o conhecimento da maior diversidade possível de línguas: "El lenguaje nos ayuda a capturar el mundo, y cuanto menos lenguaje tengamos, menos mundo capturamos. O más deficientemente. Una mayor capacidad expresiva supone una mayor capacidad de comprensión de las cosas." (CARRETER, 2004, p. 19-20).

Todas essas problemáticas são exploradas a partir de gêneros diversos (conto, história em quadrinhos, poemas etc.) os quais se materializam em textos - lidos ou produzidos pelos alunos. Segundo os Parâmetros Curriculares Nacionais (PCNs),

No trabalho com os conteúdos previstos nas diferentes práticas, a escola deverá organizar um conjunto de atividades que possibilitem ao aluno desenvolver o domínio da expressão oral e escrita em situações de uso público da linguagem, levando em conta a situação de produção

\footnotetext{
7 As atividades do PIBID voltadas à Língua Espanhola acontecem, em especial, em Cerro Largo, em virtude de esse campus estar inserido em uma região de fronteira, próxima de países hispano falantes, como Argentina e Uruguai, e cujas relações estabelecidas, através do Mercosul, estreitam contatos comerciais e culturais.
} 
social e material do texto (lugar social do locutor em relação ao(s) destinatário(s); destinatário(s) e seu lugar social; finalidade ou intenção do autor; tempo e lugar material da produção e do suporte) e selecionar, a partir disso, os gêneros adequados para a produção do texto, operando sobre as dimensões pragmática, semântica e gramatical. (BRASIL, 1998, p. 49).

Em vista disso, o gênero é entendido como um instrumento que possibilita não só abordar as questões sociais, mas também desenvolver a competência discursiva dos alunos. Schneuwly (2004), ao se fundamentar em uma perspectiva marxista, ressalta considerações dessa corrente que enfatizam a importância da mediação, e, nesse caso, do instrumento, nas relações sociais. $\mathrm{O}$ instrumento, ao mediar a relação entre o sujeito e o objeto, apresentaria um caráter social e poderia ser considerado um fator de desenvolvimento de capacidades individuais, já que, nesses casos, "[...] a ação é mediada por objetos específicos, socialmente elaborados, frutos das experiências das gerações precedentes, através dos quais se transmitem e se alargam as experiências possíveis." (SCHNEUWLY, 2004, p. 23). Nesse contexto, o autor entende que, no ensino de língua, os gêneros textuais podem funcionar como instrumentos os quais orientam comportamentos e podem construir representações diferenciadas sobre o contexto de ação.

Acreditamos que essas ações propiciam a formação de um profissional crítico, o qual, envolvido em questões sociais, dedica-se em promover, em suas aulas, um ambiente de reflexão e de conscientização, a fim de desenvolver, de fato, a cidadania de seu aluno a partir do uso da linguagem. Nesse contexto, baseados em uma perspectiva sociointeracionista, acreditamos que, ao agir sobre o ambiente em que está inserido e ao tentar modificá-lo, o sujeito modifica a si mesmo, numa relação dialética entre interioridade e exterioridade. Desse modo, a linguagem, "[...] entendida como atividade constitutiva do conhecimento humano", tem papel central, visto que é, simultaneamente, “[...] estruturante do 
nosso conhecimento e extensão (simbólica) de nossa ação sobre o mundo." (MORATO, 2004, p. 317).

\section{O REINO DAS PALAVRAS REVISITADO: O PLANEJAMENTO DE UM LIVRO DIDÁTICO DE LITERATURA}

Outra ação proposta pelo PIBID Letras - Português e Espanhol da UFFS foi a criação de um livro didático destinado a dinamizar a leitura literária que abrangesse todos os anos do Ensino Fundamental - Séries Finais e o Ensino Médio. Em observação de livros didáticos, as unidades referentes ao estudo de autores e textos literários passaram por modificações de tratamento e desenvolvimento no ensino: há a apresentação de poemas e contos na íntegra, há uma contextualização histórico-social das produções dos autores, há um cuidado com as atividades propostas, buscando unir a compreensão à interpretação textual. Contudo, ainda notamos certa dificuldade de trabalho, por exemplo, com romances ou textos maiores - o que leva os livros didáticos a explorarem apenas fragmentos. Da mesma forma, muitas atividades de pré ou pós-leitura se restringirem apenas ao "garimpo" de informações ou a margear o texto, tornando-o pretexto e sem desenvolver uma interação efetiva (e afetiva) do leitor com as obras.

Tal atividade demandou um planejamento individual e coletivo, pois cada bolsista do PIBID selecionou um autor de língua portuguesa para, a partir do conjunto de suas obras, desenvolver atividades que se espraiassem do $6^{\circ}$ ano Ensino Fundamental ao $3^{\circ}$ ano Ensino Médio. Propôs-se, então, um mergulho na obra do autor e a posterior análise de quais textos seriam possíveis de se trabalhar em sala de aula. Da mesma forma, coletivamente se pensavam diferentes atividades e avaliações, para possibilitarmos uma grande gama de abordagens em torno da literatura. Isso se tornou extremamente salutar, pois, por um lado, fez-se o movimento de levar para a sala de aula, por exemplo, Rachel de Queiroz, José 
Saramago, Lima Barreto e Pepetela e exercitar a leitura em todos os níveis de ensino. Por outro, permitiu que os acadêmicos observassem como tais autores não são exclusivos de um público erudito, como se crianças e adolescentes não pudessem compreender e exercitar a fruição literária de autores para "adultos".

O livro didático Mergulhando no reino das palavras, portanto, dividiu-se em três seções: 1 ) as atividades dos autores, inseridas por ano; 2) textos norteadores dos gêneros textuais mais comumente utilizados em sala de aula, produzidos pelas professoras supervisoras; e 3) breves contextualizações históricas, sociais e biográficas dos autores. A título de exemplo, apresentamos, em síntese, as atividades propostas em torno da obra de Fernando Pessoa.

No $6^{\circ}$ ano, conforme a Base Nacional Comum Curricular (BNCC) aponta no eixo Educação Literária, explora-se a habilidade de "Identificar, em textos em versos, aspectos rítmicos e sonoros (rimas e organização em estrofes), recursos expressivos semânticos (figuras de linguagem) e nível gráfico-espacial (distribuição da mancha gráfica no papel)" (BRASIL, 2018, p. 125). Assim, como forma de estimular o contato inicial dos alunos com o gênero poético, depois do uso das explanações contidas no texto norteador desse gênero textual, utilizam-se as Quadras ao gosto popular, de Fernando Pessoa. Depois da compreensão do gênero, e separando os versos de um conjunto de poemas, propõe-se a atividade de (re)construir ou re(inventar) novas quadras, justamente para incentivar uma leitura participativa que, ao mesmo tempo em que visualiza os sentidos propostos pelo autor, também se protagoniza como produtor de novos sentidos.

No $7^{\circ}$ ano, avançando-se na forma literária e também partindo das informações sobre o gênero textual "poema", a atividade proposta parte de um poema "infantil" de Pessoa: "No comboio descendente": "No comboio descendente / Vinha tudo à

${ }^{8}$ Esse poema foi musicado pelo cantor Zeca Afonso. 
gargalhada. / Uns por verem rir os outros / E outros sem ser por nada / No comboio descendente / De Queluz à Cruz Quebrada... [...]" (PESSOA, 2007, p. 20-21). Pensando no jogo elaborado pelo poeta, de criar uma conexão entre dois lugares e buscar criar uma unidade de sentido em que o ritmo e a rima, tal atividade se propõe a estimular a exploração do espaço geográfico e toponímico da região de abrangência da escola. Então, depois de breve contextualização do autor e de seu contexto de produção, bem como de tomar-se como base o gênero textual "poema", com encaminhamentos sobre escansão e estrutura, faz-se o exercício de produção de estrofes que evoquem o mesmo jogo, de modo que se forma o itinerário do comboio a partir dos poemas produzidos.

Efetuando-se uma conexão didática entre os $8^{\circ}$ e $9^{\circ}$ anos, explora-se uma das produções mais conhecidas de Pessoa, embora não explicada com a detença e envolvimento necessários: a poesia heteronímica. Por esse motivo, no $8^{\circ}$ ano, faz-se um movimento de aproximação do aluno com o universo pessoano dos heterônimos, partindo da carta escrita a Adolfo Casais Monteiro e as informações que o próprio poeta cria para Alberto Caeiro, Ricardo Reis e Álvaro de Campos. Enfatizando o plano dramático de "outrar-se", e propondo como atividade mobilizadora a criação de um/uma poeta, chega-se à leitura de fruição de poemas selecionados e significativos dos três heterônimos, presentes nas Ficções do Interlúdio, em associação com a poesia do Ortônimo inserida no Cancioneiro. No $9^{\circ}$ ano, por sua vez, intenta-se recuperar tais informações e estimular o exercício dramático, por meio da encenação/declamação de poemas. Dentre as múltiplas possibilidades existentes, destacamos o valor da declamação poética, que atentando-se ao ritmo, à impostação de voz e que, tornando-se uma prática, tende a desmistificar a ideia de que poesia é "difícil de ler".

Se, no Ensino Fundamental, as atividades focam-se na fruição literária e na produção estética e criativa, no Ensino Médio, pode-se desenvolver um trabalho de análise textual mais 
aprofundado e voltado para a interpretação poética. Nesse sentido, no $1^{\circ}$ ano do Ensino Médio, ampliam-se as leituras do Ortônimo e dos Heterônimos inicialmente elaboradas nas atividades citadas, inclusive com poemas de maior extensão. Podemos mencionar, a título de ilustração, poemas como "Tabacaria", de Álvaro de Campos, "Ouvi contar que outrora, quando a Pérsia..., de Ricardo Reis, o poema quinto do Guardador de rebanhos, de Alberto Caeiro, ou "Chuva Oblíqua", de Fernando Pessoa. Em todos, a partir de um conjunto de perguntas de natureza interpretativa, e em associação com outros poemas, forma-se uma proposta de discussões poéticas dos quatro autores em torno de um tema em comum. Com isso, há um exercício de uma maior compreensão do projeto poético de Fernando Pessoa bem como o envolvimento dos alunos com material poético para leitura e análise.

Por fim, em um movimento similar ao da Heteronímia, as atividades previstas para os $2^{\circ}$ e $3^{\circ}$ anos dedicam-se a uma obra dificilmente abordada no contexto escolar de Ensino Médio: Mensagem. Nessa obra, com 44 poemas, trata-se questões múltiplas referentes à fundação do reino de Portugal, às Grandes Navegações e ao ideal sebastianista, de modo que tal livro se constrói com uma base histórica, literária e linguística e que, mesmo em dimensões sintéticas, fornece uma face de Fernando Pessoa que o torna um dos mais importantes poetas do século XX.

Ao se abordar tal livro no $2^{\circ}$ ano, a proposta encaminha-se para a leitura e análise de uma seleção de poemas das três partes do livro ("Brasão", "Mar português" e "O Encoberto") e posterior realização de fichas de leitura pelos alunos, no sentido de problematizarem os sentidos presentes nos poemas, na obra como um todo e no contexto de produção e evocação da obra. No $3^{\circ}$ ano, por sua vez, depois de uma revisão da mesma obra, e um trabalho com o gênero textual roteiro, pode-se proceder à realização de curtas-metragens ou podcasts em que se expliquem ou analisem tais poemas, de modo a produzirem um material de apoio à obra de Pessoa. 
Como percebemos, as atividades não são, necessariamente, restritas ao ano de referência, mas todas se podem aplicar em qualquer nível de ensino, pois a obra de Fernando Pessoa (assim como a dos demais autores inseridos no livro didático) pode atingir e fazer-se significativa a diferentes públicos. É por meio do mergulho nos textos, no ato da leitura e na socialização, que se vai construindo uma conscientização crítica do que se leu e do como se compreenderam os sentidos do texto. Tais atividades, postas em forma de unidades didáticas de ensino, não devem ser tomadas como produções estanques, mas como sugestões para o trabalho em sala de aula com textos literários, ampliando-se o leque de repertório e abordagens possíveis.

\section{CONSIDERAÇÕES FINAIS}

O PIBID é um importante Programa de incentivo à formação de docentes em nível superior para a Educação Básica, o qual pode proporcionar melhorias nas escolas. Uma delas diz respeito à formação do futuro professor e sua qualificação, uma vez que, com a inserção no ambiente escolar propiciada pelo Programa, esse estudante vivenciará, desde o início do curso, a dialética entre teoria e prática possibilitada pela formação teórica, pela vivência da realidade escolar e pela prática, a partir da intervenção nesse domínio. Fatores que, conjuntamente, resultarão em futuros professores mais seguros, experientes e competentes, os quais desenvolverão sua autonomia profissional e sua práxis, ocasionando melhoria do contexto escolar, já que esses trabalhadores qualificados provavelmente atuarão nesse espaço.

Outro ponto importante é a possibilidade de integração entre o Ensino Superior e a Escola, a qual conecta alunos universitários em processo de formação à experiência dos professores atuantes no contexto escolar. Essa aproximação colaborativa, de um lado, permite socializar com a escola problemáticas vinculadas às 
pesquisas que são realizadas no meio acadêmico e, de outro, promove a emergência em um contexto real, o qual possibilita o (re) conhecimento de problemas relacionados ao processo de ensino e de aprendizagem e a busca de soluções. Esse estreitamento de laços, ao promover a interação dessas instâncias e a troca de experiências, materializa, de fato, o tão necessário diálogo entre Escola Básica e Ensino superior.

Essa proximidade maior entre todos os envolvidos no Programa abre espaços para que a escola possa pronunciar suas necessidades e angústias sempre transparecendo a realidade escolar, com isso, auxiliando nas descobertas e iniciativas dos pibidianos e, também, dos professores que atuam na escola. Sendo assim, o PIBID passa a ser um instrumento articulador que vai promover um movimento na escola, como espaço de decodificação da realidade social.

A complexidade do contexto educacional faz aflorar espaços de discussão e mobilização sobre novos modos de produção do saber, planejamento de ações a serem desenvolvidas e produção de materiais didáticos a serem utilizados. Por meio da interação com os alunos do PIBID, os professores mais experientes poderão refletir e ressignificar sua prática em sala de aula, elementos essenciais para o aperfeiçoamento e a inovação. Atividades diversificadas e criativas trazidas pelos bolsistas tendem a proporcionar mais disposição ao corpo docente de Ensino Básico e empolgação aos escolares.

$\mathrm{Na}$ medida em que o pibidiano passa a conhecer a realidade dos estudantes, poderá priorizar práticas que provoquem a inquietude dos alunos, tornando-os personagens ativos do aprendizado. Os estudantes ganham mais independência e interesse quando podem se sentir envolvidos no processo de união entre teoria e prática, passando a perceber que o que estuda na escola auxilia nas atividades de seu cotidiano.

Com isso, consideramos que o PIBID é um Programa que forma um perfil profissional dinâmico, criativo e reflexivo. Além disso, há que se considerar, também, que essa política de formação de professores é um caminho promissor à valorização do 
magistério e à potencialização da escola na busca por melhor qualidade educativa.

\section{REFERÊNCIAS}

BARROS LEAL, Regina. Planejamento de ensino: peculiaridades significativas. Revista Iberoamericana de Educación, [s.l.], v. 37, n. 3, p. 1-7, 2005. Disponível em: https://rieoei.org/RIE/article/view/2705. Acesso em: 8 abr. 2019.

BRASIL. Ministério da Educação. Base Nacional Comum Curricular: educação é a base. 2018. Disponível em: http://basenacionalcomum. mec.gov.br/ Acesso em: 6 abr. 2019.

BRASIL. Ministério da Educação. Parâmetros Curriculares

Nacionais: terceiro e quarto ciclos do Ensino Fundamental - Língua Portuguesa. Brasília, DF: MEC/SEF, 1998.

CARRETER, F. L. Entrevista sobre: el español, una lengua diversa. EL PAÍS: 4 fev. 2004. Entrevista concedida a Javier R. Marcos.

GERALDI, Join Wanderley. A aula como acontecimento. São Carlos: Pedro \& João Editores, 2010.

MENEGOLLA, Maximiliano; SANT'ANNA, Ilza Martins. Por que planejar? Como planejar? 22. ed. Petrópolis: Vozes, 2012.

MORATO, Edwiges Maria. O interacionismo no campo lingüístico. In: MUSSALIN, Fernanda; BENTES, Anna Cristina (org.). Introdução à lingüística: fundamentos epistemológicos. São Paulo: Cortez, 2004.

PESSOA, Fernando. Comboios, saudades, caracóis. São Paulo: FTD, 2007.

SCHNEUWLY, Bernard. Gêneros e tipos de discurso: considerações psicológicas e ontogenéticas. In: SCHNEUWLY, Bernard; DOLZ, Joaquim. Gêneros orais e escritos na escola. Campinas: Mercado das Letras, 2004. p. 21-39. 